Revista de la red interuniversitaria de estudios sobre las literaturas rioplatenses contemporáneas en Francia

16 | 2017

Esnobismos

\title{
La política de la pose
}

\section{Sylvia Molloy}

\section{OpenEdition}

\section{Journals}

\section{Electronic version}

URL: http://journals.openedition.org/lirico/3576

DOI: $10.4000 /$ lirico.3576

ISSN: 2262-8339

\section{Publisher}

Réseau interuniversitaire d'étude des littératures contemporaines du Río de la Plata

\section{Electronic reference}

Sylvia Molloy, «La política de la pose », Cuadernos LIRICO [En línea], 16 | 2017, Puesto en línea el 23 septiembre 2017, consultado el 30 abril 2019. URL : http://journals.openedition.org/lirico/3576 ; DOI 10.4000/lirico.3576

This text was automatically generated on 30 April 2019

\section{(c) (i) (9)}

Cuadernos LIRICO está distribuido bajo una Licencia Creative Commons Atribución-NoComercialSinDerivar 4.0 Internacional. 


\section{La política de la pose}

\section{Sylvia Molloy}

Publicado en Poses de fin de siglo: Desbordes del género en la modernidad (Buenos Aires, Eterna Cadencia Editora, 2012, pp. 41-53). Agradecemos a Sylvia Molloy y Leonora Djament su autorización para reproducirlo.

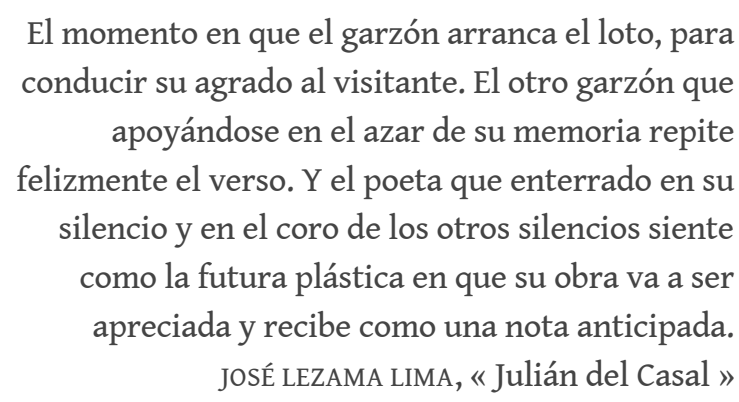

1 En un simposio que tuvo lugar hace años intenté resumir el tema que me ocupa en este libro, es decir las economías del deseo en la América latina finisecular, considerando cómo esas economías marcaban lo que podría llamarse de manera muy general, las políticas culturales del modernismo. Concretamente, dedicaba especial atención al tema del que vengo hablando, es decir, la desazón que provoca en ciertos intelectuales de la época la figura de Oscar Wilde. Mi trabajo intentaba recuperar aquel momento, fugaz y sin duda utópico, en que los dos «lados » de Wilde, el frívolo, si se quiere, y el político, podían pensarse juntos antes de que la presión de la ideología los separara, supeditando el primero al segundo hasta hacerlo desaparecer.

2 A juzgar por la reacción de uno de los moderadores, la ambivalencia y la desazón no se limitaban al siglo pasado, ya que su comentario, cediendo a su vez a una ideología vuelta naturalizado hábito de lectura, retuvo uno solo de esos aspectos de Wilde, el que llamaré, por conveniencia, el frívolo. Pasó a considerar la relación entre Wilde e Hispanoamérica en términos de mímica y de mistificación, recalcando su ligereza de gesto superfluo : en Hispanoamérica se había jugado a ser (o parecer : volveré sobre esta diferencia) Wilde, como quien se pone un disfraz o se coloca un clavel verde en la solapa. El decadentismo era, sobre todo, cuestión de pose $e^{1}$. 
3 Esta reacción no estaba tan lejos de cierta lectura de la lectura finisecular que se hizo en la época misma, aquella lectura que veía la pose como etapa pasajera correspondiente a un primer modernismo de evasión, distinto de un segundo modernismo americanista, el que era "de veras». Fue esa, por ejemplo, la lectura de Max Henríquez Ureña. A propósito de las « Palabras liminares » de Darío a Prosas profanas, escribe : «Rubén asume una pose, no siempre de buen gusto : habla de su espíritu aristocrático y de sus manos de marqués [...]. Todo esto es pose que desaparecerá más tarde, cuando Darío asuma la voz del Continente y sea el intérprete de sus inquietudes e ideales $»^{2}$.

4 Desdeñada como frívola, ridiculizada como caricatura, o incorporada a un itinerario en el que figura como etapa inicial y necesariamente imperfecta, la pose decadentista despierta escasa simpatía. Yo quisiera proponer aquí otra lectura de esa pose : verla como gesto decisivo en la política cultural de la Hispanoamérica de fines del XIX ; verla, sí, como capaz de expresar, si no "la voz del Continente ", por cierto una de sus muchas voces, $y$ verla precisamente como comentario de las «inquietudes e ideales » de ese continente. Quiero considerar la fuerza desestabilizadora de la pose, fuerza que hace de ella un gesto político.

\section{Dar a ver : el cuerpo (en) público}

5 En el siglo XIX las culturas se leen como cuerpos : piénsese en las lecturas anatómicas que hace Sarmiento tanto de España como de la Argentina, o en las enfermedades de occidente, considerado organismo vivo, vaticinadas por Max Nordau, para dar tan solo dos ejemplos. A su vez, los cuerpos se leen (y se presentan para ser leídos) como declaraciones culturales. Para reflexionar sobre el trabajo de pose, quiero rescatar ese cuerpo, recalcar su aspecto material, su inevitable proyección teatral, sus connotaciones plásticas; ver qué gestos acompañan, antes bien determinan, la conducta del poseur. Pensar sobre todo cómo se construye un campo de visibilidad dentro del cual la pose es reconocida como tal y encuentra una coherencia de lectura.

6 La exhibición, como forma cultural, es el género preferido del siglo XIX, la escopofilia, la pasión que la anima. Todo apela a la vista y todo se especulariza: se exhiben nacionalidades en las exposiciones universales, se exhiben nacionalismos en los grandes desfiles militares (cuando no en las guerras mismas concebidas como espectáculos), se exhiben enfermedades en los grandes hospitales, se exhibe el arte en los museos, se exhibe el sexo artístico en los « cuadros vivos » o tableaux vivants, se exhiben mercaderías en los grandes almacenes, se exhiben vestidos en los salones de modas, se exhiben tanto lo cotidiano como lo exótico en fotografías, dioramas, panoramas. Hay exhibición y también hay exhibicionismo. La clasificación de la patología (« obsesión morbosa que lleva a ciertos sujetos a exhibir sus órganos genitales») data de 1866; la creación de la categoría individual, exhibicionista - categoría que marca el paso del acto al individuo -, de 1880 .

7 Exhibir no solo es mostrar, es mostrar de tal manera que aquello que se muestra se vuelva más visible, se reconozca. Así, por ejemplo, los fotógrafos de ciertas patologías retocaban a sus sujetos para visibilizar la enfermedad: como muestran los archivos médicos de la ciudad de París, a las histéricas se les pintaban ojeras, se las demacraba, a efectos de representar una enfermedad que carecía de rasgos definitorios. Me interesa esa visibilidad acrecentada en la medida en que es indispensable para la pose finisecular. 
Manejada por el poseur mismo, la exageración es estrategia de la provocación para no pasar desatendido, para obligar la mirada del otro, para forzar una lectura, para obligar un discurso. No difiere esta estrategia del maquillaje, tal como lo entiende Baudelaire: « el maquillaje no ha de esconderse o evitar ser descubierto ; al contrario, debe exhibirse, si no con afectación, por lo menos con una suerte de candor $»^{3}$.

8 El fin de siglo procesa esa visibilidad acrecentada de maneras diversas, según dónde se produce y según quién la percibe Así, la crítica, el diagnóstico o el reconocimiento simpático (o antipático) son posibles respuestas a ese exceso, a la vez que son, no hay que olvidar, formas de una escopofilia exacerbada. Mírese desde donde se mire, el exceso siempre fomenta lo que Felisberto Hernández llamaría más tarde « la lujuria de ver ».

\section{Jugar al fantasma}

9 En dos ocasiones, al hablar de un « raro », recurre Darío a un precepto de la cábala citado por Villiers de l'Isle Adam en La Eva futura: «Prends garde! En jouant au fantôme, on le devient $»^{4}$. En el ensayo de Los raros dedicado a Lautréamont, escribe en efecto Darío : « No sería prudente a los espíritus jóvenes conversar mucho con ese hombre espectral, siquiera fuese por bizarría literaria o gusto de un manjar nuevo. Hay un juicioso consejo de la Kábala : No hay que jugar al espectro, porque se llega a serlo $»^{5}$. Y en « Purificaciones de la piedad», artículo publicado a los pocos días de la muerte de Oscar Wilde, observa Darío, como ya he mencionado, que « desdeñando el consejo de la cábala, ese triste Wilde jugó al fantasma y llegó a serlo » ${ }^{6}$. En ambos casos la frase se usa de manera admonitoria, para señalar los excesos de dos escritores y las trampas de una simulación que tuvo consecuencias funestas. Pero el giro interpretativo que da Darío a la frase es curioso. Jugar al fantasma y llegar a serlo supondría un afantasmamiento, una desrealización, un volverse no-tangible o no-visible. En cambio, la frase de Darío parece indicar lo contrario : un exceso de visibilidad, de presencia. Aplicada a Wilde, que es el «fantasma » que aquí me interesa, significa que el juego de Wilde se volvió excesivamente visible, y que ese exceso llevó a Wilde a su ruina. Wilde juega a ese algo que no se nombra y de tanto jugar a ese algo - de tanto posar a ese algo - da visibilidad, llega a ser ese algo innombrable.

10 No está de más recordar aquí la densa textura semántica que adquirió el término « posar » en los procesos judiciales de Wilde. En carta a su hijo Lord Alfred Douglas del $1^{\circ}$ de abril de 1894, escribe el marqués de Queensberry : « No es mi propósito analizar esta intimidad [se refiere a la relación entre Wilde y su hijo], y no hago denuncias. Pero en mi opinión posar a algo es tan malo como serlo [to pose as a thing is as bad as to be it] $»^{7}$. Cuando unos meses más tarde se presenta Queensberry en casa de Wilde, lo acusa nuevamente de pose : « No digo que usted lo sea, pero lo parece, y posa a serlo, lo que es igualmente malo $»^{8}$. En carta a su suegro, por la misma época, escribe Queensberry : « $\mathrm{Si}$ estuviera seguro del asunto [the thing], mataría al tipo de inmediato, pero solo puedo acusarlo de posar ${ }^{9}$. Por fin, el 18 de febrero de 1895, a manera de provocación, deja Queensberry una tarjeta para Wilde en el Albermarle Club de Londres con la errata que pasó a ser célebre: "To Oscar Wilde posing Somdmite»-para Oscar Wilde, que posa de somdomita [sic] »-. El resto, como dicen, pertenece a la historia.

11 Lo que no se nombra (el algo, el lo, el asunto) es desde luego el ser homosexual de Wilde, lo que no cabe en palabras porque no existe todavía como concepto (es decir, el homosexual como sujeto), pero que el cuerpo, los gestos, la pose de Wilde anuncian ${ }^{10}$. «Es importante 
recordar - escribe Moe Meyer - que Wilde no fue procesado inicialmente por actividad sexual perversa (sodomía) sino por un acto perverso de significación (posar de sodomita) Fue inicialmente un reo semiótico, no un reo sexual ${ }^{11}$. Que la corona iniciara luego un segundo proceso, acusando a Wilde ya no de posar sino de ser, muestra la fuerza identificatoria de esa pose. La pose abría un campo político en el que la identificación - en este caso, el homosexual - empezaba a cobrar cuerpo, era re-presentado, inscripto. Los juicios de Wilde, iniciados por la denuncia de una pose, brindaron un espacio de clasificación. Como observa Jeffrey Weeks, «Los juicios no solo fueron muy dramáticos, fueron altamente significativo en que crearon una imagen pública para el homosexual $»^{12}$.

\section{El amaneramiento voulu}

12 Si bien no toda pose finisecular remite directamente al homosexual, sujeto en vías de ser formulado y para cuya formulación, tanto cultural como específicamente legal, será decisivo el aporte de Wilde, el concepto de pose remite a un histrionismo, a un derroche, y a un amaneramiento tradicionalmente signados por lo no masculino, o por un masculino problematizado ; amaneramiento que, a partir de Wilde, y acaso más en Hispanoamérica que en Europa (volveré sobre este punto), se torna cada vez más sospechoso, sujeto de ese ya mencionado pánico teorizado por Eve Sedgwick ${ }^{13}$. Es decir, la pose finisecular - y aquí está su aporte decisivo a la vez que su percibida amenaza - problematiza el género, su formulación y sus deslindes, subvirtiendo clasificaciones, cuestionando modelos reproductivos, proponiendo nuevos modos de identificación basados en el reconocimiento de un deseo más que en pactos culturales, invitando a (jugando a) nuevas identidades. Se trata ahora no meramente de actitudes - languidez, neurastenia, molicie -, sino de la emergencia de un sujeto y, se podría agregar, atendiendo a las connotaciones teatrales del término, de un nuevo actor en la escena político-social.

13 En Hispanoamérica, la pose finisecular plantea nuevos patrones de deseo que perturban y tientan a la vez. Por eso - para conjurar su posible carga transgresiva, por lo menos homoerótica - se la suele reducir a la caricatura o neutralizar su potencial ideológico viéndola como mera imitación. Se la acepta como detalle cultural, no como práctica social y política. Se la reduce al afeminamiento jocoso ; para citar a un crítico, a « una fastidiosa cháchara de snobs que van a nuestras selvas vírgenes con polainas en los zapatos, monóculo impertinente en el ojo, y crisantemo en el ojal $»^{14}$.

\section{Pose y patología}

14 En su mencionada reseña acerca del « piadoso y definitivo libro » de Edmond Lepelletier sobre Verlaine, escribe Rubén Darío :

Los amigos de asuntos tortuosos se encontrarán desilusionados al ver que lo referente a la famosa cuestión Rimbaud se precisa con documentos en que toda perspicacia y malicia quedan en derrota, hallándose, en último resultado, que tales o cuales afirmaciones o alusiones en prosa o verso no representan sino aspectos de simulación, tan bien estudiados por Ingegnieros [sic]. ${ }^{15}$

La cita de Darío me lleva a reflexionar sobre un último aspecto de la pose. No en la pose como signo de amaneramiento, como visibilización de la no-masculinidad, sino en el amaneramiento, la visibilización de la no-masculinidad - la homosexualidad, en el caso preciso de Verlaine - como pose. Aparentemente se trata de una simple inversión de 
términos. Propongo que la inversión es algo más, que los términos no son exactamente reversibles ni equivalentes, que su inversión imprime una nueva dirección en lo que podríamos llamar la epistemología de la pose. El doble itinerario sería el siguiente : 1) la pose remite a lo mentado, al algo cuya inscripción la constituye la pose misma: la pose por ende representa, es una postura significante ; pero 2) lo no mentado, una vez inscripto y vuelto visible, se descarta ahora como " pose »: una vez más la pose representa (en el sentido teatral del término) pero como impostura significante. Dicho aún más simplemente : la pose dice que se es algo, pero decir que se es ese algo es posar, o sea, no serlo.

La cita de Darío también me sirve como introducción a la obra de quien se empeñó en trabajar la pose clínicamente con ejemplar ahínco, incorporándola a su sitema a la vez como patología y como terapia. Hablo por supuesto de José Ingenieros - que no es Ingegnieros , como escribe Darío, sospecho que no inocentemente -, quien dedica buena parte de su investigación psiquiátrica al estudio de la simulación, transformándola de fenómeno puramente biológico de adaptación (el mimetismo animal) en categoría moral negativa. La simulación, para Ingenieros, es una estrategia de adaptación que importa un falseo, y es po rende moralmente objetable, es « un medio fraudulento de lucha por la vida ${ }^{16}$. [E]n la simulación - añade - las apariencias exteriores de una cosa o acción hacen confundirla con otra, sin que efectivamente le equivalga» ( $\mathrm{S}$, p. 123 ; subrayado en el original). Para Ingenieros, no se puede simular (posar) ser lo que se es : la pose necesariamente miente ${ }^{17}$.

And yet, and yet... Hay un curioso desliz, en una serie de ejemplos en La simulación en la lucha por la vid, que seriamente cuestiona esta aseveración :

El ambiente impone la fraudulencia: vivir, para el común de los mortales, es someterse a esa imposición, adaptarse a ella.

Quien lo dude, imagínese por un momento que el astuto especulador no simule honestidad financiera; que el funcionario no simule defender los intereses del pueblo; que el literato adocenado no simula las cualidades de los que triunfan; que el comerciante no simule interesarse por sus clientes ; que el parásito no simule ser útil a su huésped, [...]; que el pícaro no simule la tontería y el superior la inferioridad, según los casos ; el niño una enfermedad, el maricón el afeminamiento [...] (S, p. 185).

18 Si no me equivoco, el último ejemplo rompe notablemente con el esquema de simulación fraudulenta: el maricón no simula ser lo que no es (como el astuto especulador que simula ser honesto) sino, podría decirse, lo que es. La simulación, la pose, parecería reforzar en lugar de reemplazar con el signo opuesto. El ejemplo no cabe pues dentro del planteo de Ingenieros a menos de imaginar una interpretación de proyección ideológica más drástica. El «maricón» es «en realidad» un hombre, por lo tanto, al simular lo femenino, posa a lo que no es. Así, el homosexual, como sujeto que trasciende las categorías del binarismo genérico, queda efectivamente eliminado en el planteo de Ingenieros, reducido a ser « en realidad » una cosa que « simula » ser la otra.

19 La actitud de vigilancia casi policíaca por parte del médico legista que efectúa «determinaciones periciales [...] de alto interés penal» con el propósito de «desenmascarar a los simuladores» $(S$, p. 254) recuerda la vigilancia de Queensberry, empeñado en ver si Oscar Wilde era o no era eso. Pero en el caso de Ingenieros, el desenmascaramiento de la pose, a la vez que confirma la pericia del diagnosticador, produce otro resultado. No lleva a la acusación sino a un desplazamiento de patologías no es, se hace ; o dicho en términos de época, no es degenerado sino simulador -, y ese desplazamiento produce una suerte de alivio cultural. No solo exime al simulador sino a 
sus supuestos modelos, de quienes nos asegura Ingenieros que «en realidad» siempre fueron fumistas, es decir, poseurs: «Entre los literatos novicios es frecuente encontrar sujetos que simulan poseer malas cualidades, creyéndolas verdaderas en los fumistas por quienes están sugestionados $\left(S\right.$, p. 259). Según Ingenieros, nadie es, todos se hacen ${ }^{18}$. Véase por ejemplo el caso siguiente :

Un joven literato [la versión previa del texto, en los Archivos de psiquiatría y criminología agrega: "decadente»], sugestionado por los fumistas franceses, creyóse obligado a simular los refinamientos y vicios fingidos po restos, conceptuándolos verdaderos. Simulaba ser maricón [la versión previa dice: «pederasta pasivo »], haschichista, morfinómano y alcoholista. [...] Todo era producto de sus pueriles sugestiones, fruto de las fumisterías de los estetas y superhombres cuyas obras leía de preferencia y bajo cuya influencia vivía, tratando de ajustar sus actos y sus ideas al «manual del perfecto literato decadente» $(S$, p. 241).

20 Otra versión del mismo caso, citada en La simulación de la locura, también de Ingenieros - fue de hecho su tesis doctoral -, añade detalles interesantes sobre el trabajo de simulación del sujeto observado :

\begin{abstract}
Al poco tiempo manifestó profunda aversión por el sexo femenino, enalteciendo la conducta de Oscar Wilde, el poeta inglés que en aquel entonces acababa de ser condenado en Londres, sufriendo en la cárcel de Reading las consecuencias de sus relaciones homosexuales con Lord Douglas. Escribió y publicó una « Oda a la belleza masculina » y llegó a manifestar que solo hallaba placer en la intimidad masculina. Algunas personas creyeron verdaderas esas simulaciones, alejándose prudentemente de su compañía; por fortuna, sus amigos le hicieron comprender que si ella podía servir para sobresalir literariamente entre sus congéneres modernistas, en cambio le perjudicarían cuando abandonara esos estetismos juveniles.

El simulador protestó que nadie tenía derecho de censurarle sus gustos, ni aun so pretexto de considerarlos simulados. Mas, comprendiendo que, al fin de cuentas, nadie creería en ellos, renunció a sus fingidas psicopatías. ${ }^{19}$
\end{abstract}

21 Que el ser visto como maricón o como pederasta pasivo se considerara en principio algo deseable y, más aún, motivo de prestigio literario es harto dudoso. Vistos los esfuerzos por blanquear vidas de escritores, ya heterosexualizándolas, ya patologizándolas, que vengo comentando, es poco probable que esta simulación (si de simulación se trata) añadiera prestigio literario a la vida de nadie en América latina. El episodio sirve en cambio para disminuir aún más al individuo, presentado como ingenuo, fácilmente sugestionable, y sobre todo poco inteligente : cree dignas de emulación conductas que ya son, como todo el mundo sabe e Ingenieros se empeña en insistir, fingidas. ${ }^{20}$

22 De qué modo, concretamente, se simula ser pederasta pasivo y de qué modo se detecta esa simulación - es decir: cuál es la pose o serie de poses que a la vez señalan una identidad e inconfundiblemente revelan su impostura - es algo que Ingenieros no explicita. El sucinto, bastante patético final del párrafo es rico en hiatos : el « simulado » pederasta pasivo « protesta », luego « comprende », luego « renuncia » : nunca sabremos, a ciencia cierta, a qué. Del mismo modo, creo que también «renuncian» las culturas hispanoamericanas del fin del siglo XIX a asumir esas poses que durante un brevísimo momento significaron más allá de su propia simulación. Vaciadas de pertinencia, quedaron arrumbadas, como utilería en desuso, en el closet de la representación para no hablar del closet de la crítica. Creo que era justo devolverles la llamativa visibilidad que alguna vez tuvieron. 


\section{NOTES}

1. El mismo trabajo, leído ante la Asociación Internacional de Hispanistas en sesión plenaria, suscitó una reacción similar por parte de una persona del público, quien preguntó si la ambivalencia de Martí y de Darío con respecto a Wilde no tendría que ver con el hecho de que estaban preocupados con algo «más importante », es decir, « la construcción de una identidad continental ».

2. Max Henríquez Ureña, Breve historia del modernismo, México, Fondo de Cultura Económica, 1962, p. 97.

3. Charles Baudelaire, «Le peintre de la vie moderne ", en Euvres complètes, Paris, Gallimard, «Pléiade », 1954, p. 914.

4. Mathieu Villiers de l'Isle Adam, L'Eve future, en Cuvres complètes I, Ginebra, Slatkine Reprints, 1970, p. 103.

5. Rubén Darío, Obras completas 2, Madrid, Afrodisio Aguado, op. cit., p. 436.

6. Ibid., t. 3, p. 471.

7. H. Montgomery Hyde, The Trials of Oscar Wilde, Londres, Dover Publications, 1973, p. 71.

8. Ibid., p. 73.

9. Ibid., p. 74.

10. Véanse al respecto las inteligentes observaciones de Alan Sinfield : «El desafío para el crítico es recuperar el momento de indeterminación. No es que la idea que tenemos hoy de 'el homosexual' se disimulara tras estos silencios, como una estatua debajo de una sábana, plenamente formada y pronta a ser revelada ». The Wilde Century: Effeminacy, Oscar Wilde and the Queer Moment, Nueva York, Columbia University Press, 1994, p. 8.

11. Moe Meyer (comp.), The Politics and Poetics of Camp, Nueva York y Londres, Routledge, 1994, p. 98.

12. Jeffrey Weeks, Coming Out: Homosexual Politics in Britain from the Nineteenth Century to the Present, Londres, Quartet, 1977, p. 21.

13. Eve Kosofsky Sedgwick, Between Men : English Literature and Male Homosocial Desire, Nueva York, Columbia University Press, 1985.

14. Pedro Emilio Coll, en Arnold L. Ulner, Enrique Gómez Carrillo en el modernismo, 1889-1896, Diss. Univ. of Missouri, 1972, p. 207.

15. Rubén Darío, Obras completas 2, op. cit., p. 718.

16. José Ingenieros, La simulación en la lucha por la vida (1903), en Obras completas I, revisadas y anotadas por Aníbal Ponce, Buenos Aires, Ediciones L. J. Rosso, 1933, p. 114 ; subrayado en el original. Las citas de esta obra aparecen de ahora en adelante directamente en el texto precedidas por $S$.

17. En otro capítulo apunta Ingenieros: «Simular [...] es adoptar los caracteres exteriores y visibles de lo que se simula, a fin de confundirse con lo simulado. La mentira, la hipocresía, la astucia, pueden asumir formas que involucren el fenómeno especial de la simulación, pero no son siempre y necesariamente simulaciones » (S, p. 209).

18. Al alivio cultural que propone Ingenieros, el « se hace » en lugar del « es », se oponen desde luego algunos textos ansiosos: el ya mencionado " estudio social» de Adolfo Batiz o la obra teatral Los invertidos (Obra realista en tres actos) de José González Castillo (1914), Buenos Aires, Puntosur Editores, 1991.

19. José Ingenieros, La simulación de la locura (1901), en Obras completas II, Buenos Aires, Ediciones L. J. Rosso, 1933, pp. 24 y 25. 
20. En otra ocasión observa Ingenieros que «D’Annunzio (italiano que ha sufrido contagios psicológicos franceses) ha simulado ser partidario del amor sororal y del homosexualismo; es verosímil considerar simulados tales 'refinamientos' del instinto sexual. Se comprende que [...] no copuló con sus hermanas o con otros hombres » ("Psicología de los simuladores », en Archivos de Psiquiatría, Criminología y Ciencias Afines, II, 1903, p. 477). Llama la atención el uso de la palabra «verosímil » en lugar, propongo, de « preferible ». También llama la atención que en una versión posterior de este texto, recogido en La simulación en la lucha por la vida, desaparece toda mención de homosexualismo. Sólo le queda a D’Annunzio la simulación del incesto, afectación, suponemos, menos peligrosa (S, p. 232). 